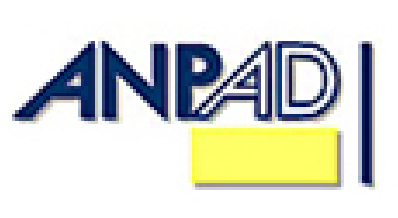

Documentos e Debates:
Disponível em

http://www.anpad.org.br/rac

RAC, Curitiba, v. 14, n. 2,

pp. 367-371, Mar./Abr. 2010

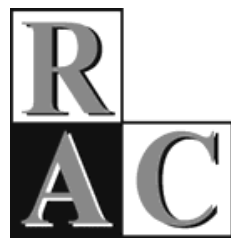

\title{
Réplica 2 - Mestrado Profissional, Você Sabe Com Quem Está Falando?
}

\author{
Professional Masters, have you seen my credentials?
}

Copyright (C) 2010 RAC. Todos os direitos, inclusive de tradução, são reservados. É permitido citar parte de artigos sem autorização prévia desde que seja identificada a fonte. 
O convite honroso para comentar um artigo sobre Mestrado Profissional é gentileza do Professor Jaime Fensterseifer. Consenti fazê-lo por algumas razões. Uma dessas razões, certamente, é a importância acadêmica do formulador do convite e da publicação em nome da qual agiu. Outra razão de grande peso é o fato de o artigo ter sido escrito pela professora Tânia Fischer, cuja contribuição ao Mestrado Profissional se inicia na própria ideia original dessa modalidade de formação. Uma terceira razão é a oportunidade que tive de participar, em 2008, de Comissão constituída no âmbito da Capes com a finalidade de apresentar propostas de regulamentação e de diretrizes para a avaliação do Mestrado Profissional. Uma razão adicional é certa perplexidade que me atinge diante das reações negativas que a proposta de nova concepção de Mestrado gerou em diversas áreas, sem que todas as suas potencialidades tivessem sido discutidas, evidenciando estar em jogo um processo assemelhado à neofobia.

Antes de iniciar os comentários propriamente ditos, e considerando que o presente texto será encaminhado à professora Tânia para a tréplica, resolvi exibir-me um pouco. A professora menciona o fato de o professor Jaime, recentemente, ter concluído uma "formação tecnológica que o habilita a produzir bons vinhos". Registro aqui ter tido a oportunidade de provar dois diferentes espumantes produzidos pelo professor Jaime como parte de seu trabalho de conclusão de curso, o que, posso assegurar, foi maravilhosa experiência sensorial, e também social, considerando a qualidade dos comensais então presentes.

Ainda como preâmbulo, retomo aqui a já mencionada participação na Comissão do Mestrado Profissional na Capes. Dessa Comissão participaram também os professores Adiel Teixeira de Almeida (UFPE), Flávio Dantas (UFU), Jaime Evaldo Fensterseifer (UFRGS), Maria Auxiliadora da Silva Campos Dessen (UnB) e Maria Leonor Lopes Assad (UFSCar). Em vários momentos, a Comissão pode contar com colaborações de funcionários da Diretoria de Avaliação da Capes e do próprio Diretor de Avaliação na época, Renato Janine Ribeiro, da USP. Faço essa menção detalhada da Comissão para assinalar que diversos dos comentários que farei resultam de amadurecimento proporcionado pelas discussões travadas ao longo do funcionamento da Comissão, não sendo fruto, exclusivamente, de reflexão individual.

O texto da professora Tânia Fischer menciona alguns aspectos históricos relativos à criação dos Mestrados Profissionais, trata da realidade atual desta modalidade de formação pós-graduada, e exemplifica alguns pontos com informações sobre a experiência inovadora e bem sucedida do Mestrado Programa de Desenvolvimento e Gestão Social da Universidade Federal da Bahia.

Essa estrutura lhe permitiu falar das dificuldades que a proposta de Mestrado Profissional enfrentou, algumas delas ainda vigorosas, e examinar uma série de tensões atuais que o tema suscita, evidenciando que a comunidade acadêmica permanece dividida quanto à utilidade ou à necessidade de uma 'nova modalidade de Mestrado' (entre aspas porque há casos em que essa novidade já está na segunda década).

A origem dessa divisão talvez esteja relacionada com duas vertentes principais. A primeira delas envolve algumas ambiguidades não resolvidas no momento do lançamento dos Mestrados Profissionais que, aliás, foram nomeados de início como Mestrados Profissionalizantes, termo assaz associado à formação em nível de Graduação e até mesmo em nível de Ensino Médio. Além desse detalhe na identificação, alguns outros pontos favoreceram a mencionada ambiguidade:

a) Foi divulgado que o título concedido pelo Mestrado Profissional não teria valor para a carreira acadêmica, assim como não permitiria pleitear ingresso no Doutorado.

b) Faltou clareza na explicitação dos elementos que diferenciavam o Mestrado Profissional dos bons cursos de especialização, naquele momento ainda existentes em muitas áreas.

c) A proposta de aceitar uma nova modalidade de formação no mesmo nível do Mestrado Acadêmico, mas reduzindo a exigência de titulação por parte dos docentes, em momento em que muitos grupos de instituições públicas e privadas, com tradição de pesquisa, ainda buscavam 
elevar a titulação de seus docentes para alcançar o patamar que lhes permitiria apresentar suas sonhadas propostas de implantação de Mestrados Acadêmicos, foi percebida por muitos como uma rasteira que, além de tudo, abriria espaço para propostas provindas de instituições de mercado que não teriam fôlego para estabelecer Mestrados Acadêmicos.

d) Não mereceu adequada exploração, o que poderia representar de novidade, a abertura para aceitação de ampla diversidade de modalidades de trabalhos de conclusão, adicionais à dissertação em moldes tradicionais, lembrando aqui que os Mestrados Acadêmicos de diversas áreas já estavam abertos à possibilidade de trabalhos de conclusão distintos dessa dissertação tradicional.

e) Os primeiros documentos divulgados diziam, eufemisticamente, que os Mestrados Profissionais tinham vocação para a autossustentação, o que reativou a discussão sobre a gratuidade do ensino público.

Em termos de contexto, vale lembrar ainda que a proposta veio a público em circunstâncias explicitadas em seguida:

. Em momento no qual a grande expansão do nível de Doutorado ainda não se havia iniciado no país, o que valorizava muito o único tipo de Mestrado então existente.

- Em momento no qual se iniciava uma era de avaliações mais detalhadas do ponto de vista técnico e que se apoiavam, fundamentalmente, na produção publicada: é importante lembrar que um dos pontos mais incisivos da reação ao Mestrado Profissional sempre foi a dificuldade de estabelecimento de critérios para avaliá-lo.

. Em momento no qual instituições privadas, com pouca tradição em pesquisa, começavam a invadir a praia da Capes, contratando muitos recém-aposentados das instituições públicas, que se assustaram com as ameaças de mudança na carreira.

- Em momento no qual o prestígio da pós-graduação ainda assegurava um dos únicos territórios atingidos com menor impacto pelo descaso governamental com as universidades.

Considere-se ainda o fato de que a ideia de Mestrado Profissional é complexa e pode assustar no primeiro contato. O texto da professora Tânia Fischer diz que a prática acadêmica no Mestrado Profissional é um desafio - concordo com ela; e acrescento: não só a prática acadêmica, mas a própria concepção de cada proposta, o que significa que é desafio caso a caso.

Aparentemente todos esses fatores contribuíram para a reação de muitos dos docentes ligados à pósgraduação e à própria Capes, docentes entre os quais, por razões óbvias, predominava uma orientação estritamente acadêmica. Foi como se os Mestrados e Doutorados Acadêmicos dissessem ao inesperado intruso: Mestrado Profissional, você sabe com quem está falando?

Em outras palavras: muitos temeram que, na contramão da elevação e da internacionalização da pósgraduação brasileira stricto sensu, o Mestrado Profissional exemplificasse a redução do nível de exigências que estaria permitindo a implantação de cursos de qualidade menor. Esse ponto também é explorado no texto que serve de base para os comentários que aqui estão sendo feitos.

Com o passar do tempo e com a consolidação dos Mestrados Profissionais em muitas áreas de conhecimento, algumas dessas questões iniciais foram parcialmente superadas, mas algumas tensões continuaram sem solução. A evidência de que muitos Programas de Pós-Graduação respeitáveis, com sede em outros países, têm características Profissionais contribuiu para isso. Uma dessas tensões que permanece, conforme aponta o texto da professora Tânia Fischer, diz respeito à composição do corpo docente. A ênfase da discussão aponta o que falta aos docentes, cuja participação é questionada: o título (na verdade, nem sempre falta esse título). Seria importante lembrar que esses docentes só participam porque algumas coisas lhes sobram: experiência profissional de alto nível, consolidada a partir de inúmeros cursos e do desenvolvimento de projetos, em sua maioria desvinculados da realidade acadêmica, até mesmo pelo distanciamento entre a Universidade e outros setores da 
sociedade. Essas informações são importantes para responder à questão tantas vezes ouvida: como alguém que nem Mestre é pode participar da formação de Mestres?

Além do mais, essa questão da titulação pode ser transitória. Considerando a grande expansão da pós-graduação no Brasil, a titulação do corpo docente de Mestrados Profissionais em pouco tempo (quem sabe uma década?) poderá ter outras características, com todos aqueles docentes não vinculados às universidades apresentando título, no mínimo, de Mestre (talvez oriundos, majoritariamente, de Mestrados Profissionais). Vale lembrar ainda que muitas carreiras profissionais não valorizavam, em termos organizacionais e salariais, os títulos de pós-graduação stricto sensu, o que já não é mais a regra.

O texto da professora Tânia Fischer deixa claro que o grande equívoco é tentar discutir o Mestrado Profissional sempre tomando como referência o eixo acadêmico, o que impede de vê-lo como estratégia de formação profissional com natureza e estrutura próprias. Não se trata de um tipo de formação pensada em termos de linhas de pesquisa, mas em termos de área de competência para a solução de problemas e para a inovação. Deve ficar claro que isso não impede que docentes/pesquisadores vinculados a tais cursos mantenham suas atividades em torno de linhas de pesquisa, mas sinaliza o interesse de que tais docentes construam sua produção intelectual de forma parcialmente devotada ao contexto de aplicação. Um mesmo docente pode atuar em Mestrados das duas modalidades, sem fazer a mesma coisa em ambos, sabendo explorar as possibilidades complementares que oferecem. No Mestrado Profissional, assim como no Acadêmico deve existir formação metodológica e pesquisa. O Mestrado Acadêmico altera suas características em função de transformações amplas de concepções e modelos nas áreas de conhecimento em que atua, e que se consolidam com certa morosidade. O Mestrado Profissional é caracterizado por maior dinamismo, pois a adaptação é uma de suas marcas, já que é movido por demandas que lhe são endereçadas.

Muitos Mestrados que estão em funcionamento hoje mesclam essas características, em diferentes proporções. Alguns Mestrados Acadêmicos são exemplos involuntários de Mestrados Profissionais interessantes. Mudanças de interesse, de possibilidades, de instrumentos, podem ser lidas pelo corpo docente de um Programa como indicação de que um Programa de determinada natureza está assumindo outras características, e que deveria passar de Acadêmico a Profissional ou vice-versa. Entendo que a regulamentação deveria prever e autorizar tal metamorfose.

O desafio da avaliação é concreto e a proposta da Comissão da qual participei era bastante radical ao diferenciar com muita clareza o processo avaliativo para Mestrados Profissionais e Acadêmicos, até mesmo trabalhando com escalas de conceito distintas. Ainda assim alguns aspectos que diferenciam o processo nos dois casos foram garantidos. A avaliação dos Mestrados Profissionais exige a relativização do princípio de comparabilidade, que está na base da avaliação dos Programas Acadêmicos. Em função dessa tradição é difícil aceitar abrir mão da aplicação desse princípio. Ocorre que os Mestrados Profissionais não precisam estar submetidos a jogar com as mesmas regras, o que inviabiliza a avaliação meramente comparativa.

A autora do texto que está sendo comentado apresenta a seguinte consideração:

Nossas tradições burocráticas e ancestralidade cartorial em um sistema centralmente regulado como é o de educação brasileira em geral e o da pós-graduação em particular, leva-nos a perguntar primeiro quais são as regras antes de criar um desenho de curso, pois o sistema de avaliação que construímos, com mérito e pelo mérito, ostenta duas faces: estimula a qualidade e reprime a criatividade e a inovação, atributos fundamentais de processos artesanais, dos quais o mestrado profissional é um exemplo pleno de significado.

Transcrevi as palavras da autora porque se trata do único ponto de seu trabalho do qual discrepo. Sua descrição é precisa, mas a visão de que o sistema de avaliação vigente estimula a qualidade, mas reprime a criatividade e a inovação me parece um pouco forçada, um pouco publicitária. Exemplos de qualidade, criatividade e inovação nos Mestrados Acadêmicos não são escassos. Minha preferência seria dizer que uma avaliação menos preocupada em estabelecer hierarquias rígidas e conformadas a 
determinados tipos de distribuição teria impacto bastante positivo sobre a qualidade, estimulando a criatividade na formação e na produção, e assegurando alta probabilidade de geração de inovações tanto em Mestrados Profissionais como em Acadêmicos.

O tema da criatividade está relacionado a outra das tensões mencionadas pela professora Tânia Fischer: a das controvérsias em torno das diferentes possibilidades de trabalhos de conclusão. É certo que muitos Mestrados Acadêmicos passaram a admitir ampla variedade de trabalhos terminais, em alguns casos constituindo modalidades de produção muito distintas de uma dissertação tradicional, como acontece, por exemplo, em Computação ou em Artes. As propostas relativas a Mestrados Profissionais ampliam bastante a variedade de trabalhos de conclusão possíveis; mas não creio que diferentes categorias de trabalhos terminais proporcionem critério apropriado para diferenciar cursos Profissionais e Acadêmicos. Em todos os casos existe produção que resultou de alguma modalidade de pesquisa e que constituiu contribuição real à literatura sobre o assunto abordado. O estímulo às experiências com modelos diversos, tanto nos casos Acadêmicos como nos casos Profissionais, mais do que estabelecer diferenças, poderá contribuir para que um incorpore os mecanismos positivos testados pelo outro.

O tema da sustentabilidade dos Programas Profissionais, também mencionado no texto que aceitei comentar, é outro ponto importante. Uma discussão sobre as características atuais dos Mestrados Profissionais poderia revelar que a exigência de financiamento independente das fontes governamentais de recursos pode representar um filtro pelo qual só passem profissionais já absorvidos por empresas ou por instituições públicas (ou porque essas empresas ou instituições estão financiando o projeto, ou porque têm renda que permite assumir essa despesa, muitas vezes alta, com a formação complementar). Interessados que não estejam em uma dessas condições terão dificuldade de se engajar em Mestrados Profissionais. Uma solução para esse impasse não poderá ser postergada indefinidamente pela Capes.

A professora Tânia Fischer foi especialmente feliz ao mencionar o Decreto ${ }^{0}$ 302, de 2007, que enfatiza a política de apoio à profissionalização, concretizada com a transformação dos Centros Federais de Educação Tecnológica [CEFETs] em Institutos Federais de Educação (IFEs), "possibilitando a abertura de cursos superiores de graduação e pós-graduação a estas instituições remanescentes, em sua maioria, das escolas técnicas e agrotécnicas de $2^{\circ}$ grau”. Esses institutos estão espalhados por todo o país. Alguns IFEs já sediam Programas de Mestrado. É provável, até por coerência com a história dessas instituições, que os Mestrados a serem gerados ali sejam, predominantemente, de natureza Profissional. Levando em conta a expansão dessas instituições e a rápida elevação da titulação dos quadros docentes que estão sendo constituídos, esses Mestrados em breve serão muitos.

Uma das facetas a serem observadas nesses casos em que a instituição oferece cursos de graduação enfeixados em uma mesma grande área é a da interação graduação/pós-graduação. No caso dos Mestrados Acadêmicos, essa interação, tradicionalmente, se faz quase exclusivamente pela via da iniciação científica e do aproveitamento dos mestrandos em atividade de estágio docência. Esta interação, no caso do Mestrado Profissional, em especial daqueles oferecidos no âmbito dos IFEs, poderá privilegiar a articulação com os estágios curriculares da Graduação e também com estágios e práticas laboratoriais e de campo que os estudantes de nível médio devem cumprir. Essa tríplice articulação, que é inovação, nenhum Programa de Pós-Graduação atual pode exibir.

Reafirmo que foi grande prazer acadêmico ler o texto da professora Tânia Fischer e encerro meus comentários propondo que a experiência que todos vivemos de perceber a dificuldade de implantar um tipo de Mestrado com características que não o tornava imediatamente reconhecível, não deve dar origem a práticas de fomentar comparações hierarquizantes e impróprias entre as diferentes modalidades, nem deve levar ao perigoso raciocínio, segundo o qual, todas as áreas devem ter Mestrados Profissionais. 